\title{
Adverse events due to unnecessary radiation exposure in medical imaging reported in Finland
}

T. Tarkiainen ${ }^{\mathrm{a}, *}$

tarja.tarkiainen@ppshp.fi

M. Haapea

marianne.haapea@ppshp.fi

\section{E. Liukkonen}

esa.liukkonen@ppshp.fi

O. Tervonen

osmo.tervonen@ppshp.fi

\section{Turpeinen}

miia.turpeinen@ppshp.fi

\section{J. Niinimäki}

jaakko.niimaki@ppshp.fi(jaakko.niinimaki@ppshp.fi)

a Department of Diagnostic Radiology, Research Unit of Medical Imaging, Physics and Technology, Oulu University Hospital, POB 50, 90029 OYS, Oulu, Finland

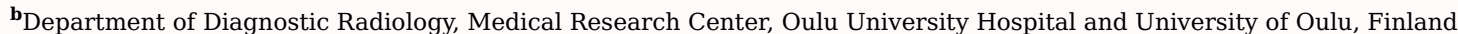

'Department of Diagnostic Radiology, Oulu University Hospital, Finland

dDepartment of Diagnostic Radiology, Research Unit of Medical Imaging, Physics and Technology, Oulu University Hospital and University of Oulu, Finland

eAdministrative Centre, Research Unit of Biomedicine, Oulu University Hospital and University of Oulu, Finland

${ }^{*}$ Corresponding author.

\section{Abstract}

\section{Introduction}

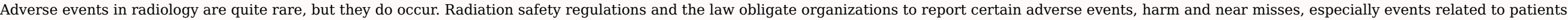
health and safety. The aim of this study was to describe and analyse incidents related to radiation safety issues reported in Finland.

\section{Methods}

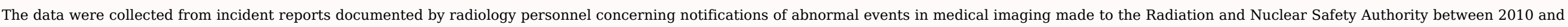

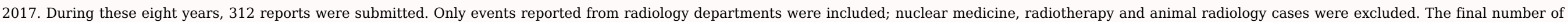
reports was $293(94 \%)$.

\section{Results}

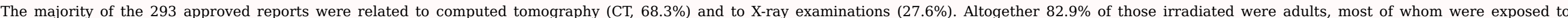

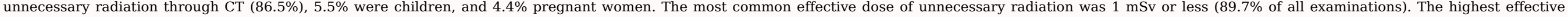

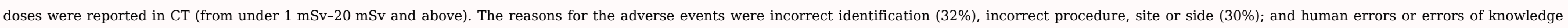


Adverse events occurred especially in CT examinations. It is important to collect and analyse incident data, assess the harmful events, learn from them and aim to reduce adverse events. Implications for practice

This study emphasizes the need for radiological personnel to obtain evidence-based information on adverse events and focus on training to improve patient safety.

Keywords: Adverse events; Incident reporting; Imaging errors; Patient safety

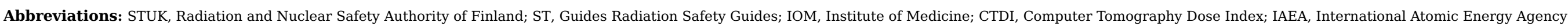

\section{Introduction}

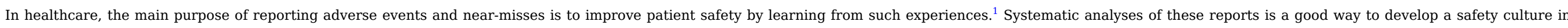

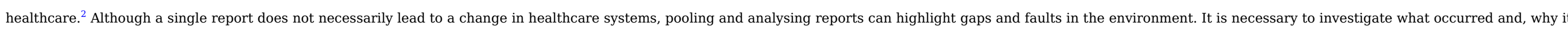
occurred, and to determine the deficiencies in the system that allowed the incident to take place.

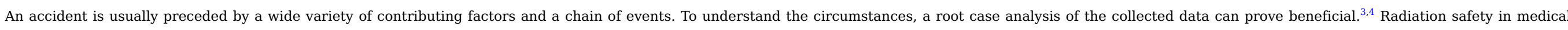

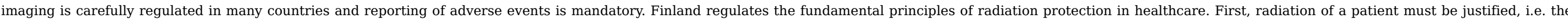

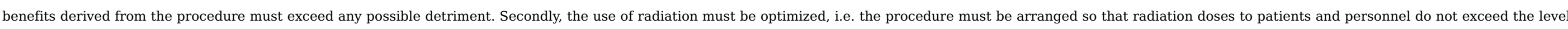

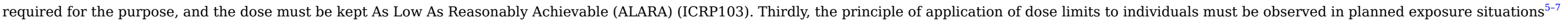

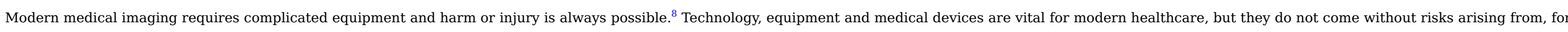

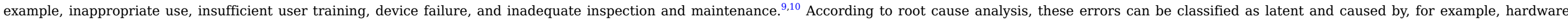
installation, materials, or protocols; or as culture-based, active, knowledge-based or skill-based. ${ }^{5}$

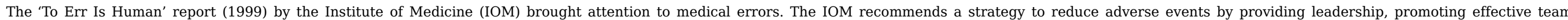

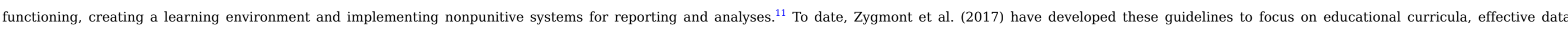
infrastructures, designed reporting systems, and validated performance measures. ${ }^{12}$

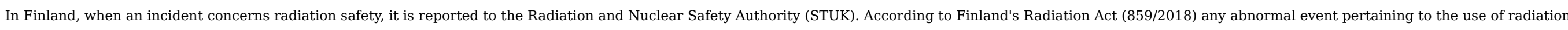

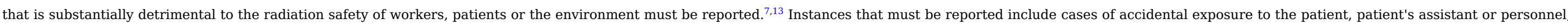

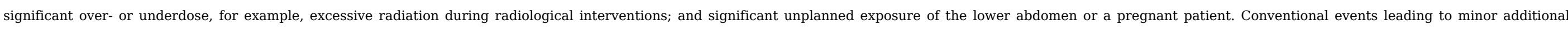
exposure (e.g. projection error, movement of patient) do not need to be reported. ${ }^{14}$

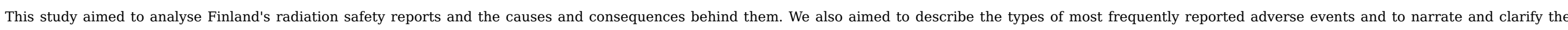
incidents that occur in medical imaging.

\section{Methods \\ Study design}

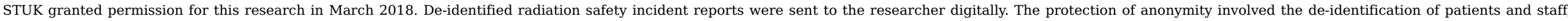
equipment manufacturers and the hospitals in which the adverse events had occurred.

\section{Data selection}




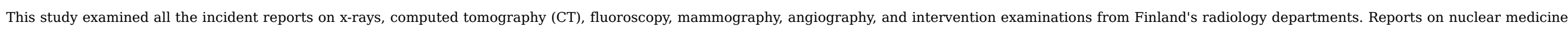

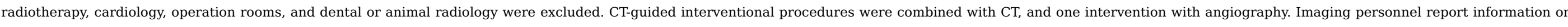

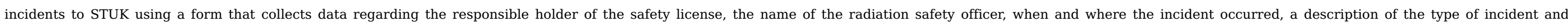
examination, persons exposed to radiation, estimated radiation dose, immediate corrective action, and the root cause.

\section{Data analysis}

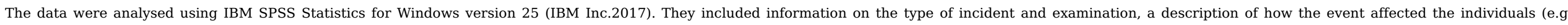

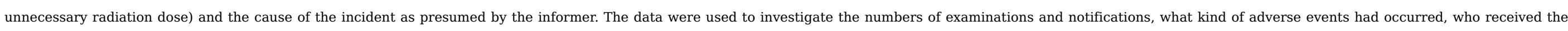

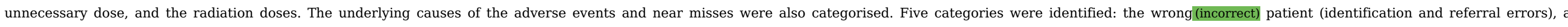
pregnant patient or staff member, equipment malfunction, human errors or errors of knowledge, and incorrect procedures, sites or side errors.

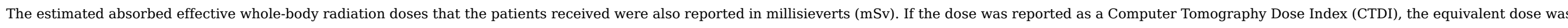

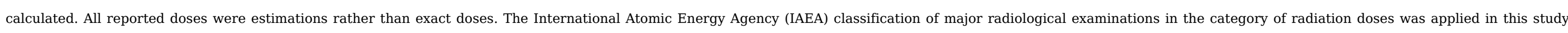
IAEA's dose categories are: 1 ) low dose of $\leq 1 \mathrm{mSv}, 2$ ) intermediate dose of $1-5 \mathrm{mSv}$ and 3) high doses of 5-20 mSv. ${ }^{15} \mathrm{~A}$ category of 4 ) high(very high) doses of $\geq 20 \mathrm{mSv}$ was added.

\section{Results}

\section{Radiology safety reports from 2010 to 2017}

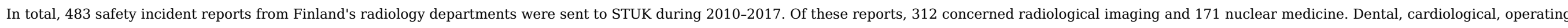

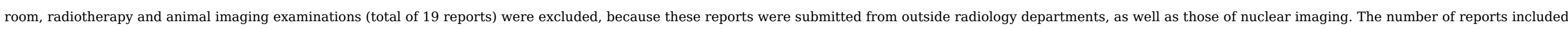
in the analysis was $\mathrm{N}=293$.

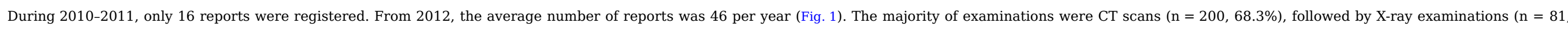
$27.6 \%)$. The combined number of fluoroscopy, mammography, angiography and interventional procedures was small $(\mathrm{n}=12.4 .1 \%)(\mathrm{n}=12,4.1 \%)$.

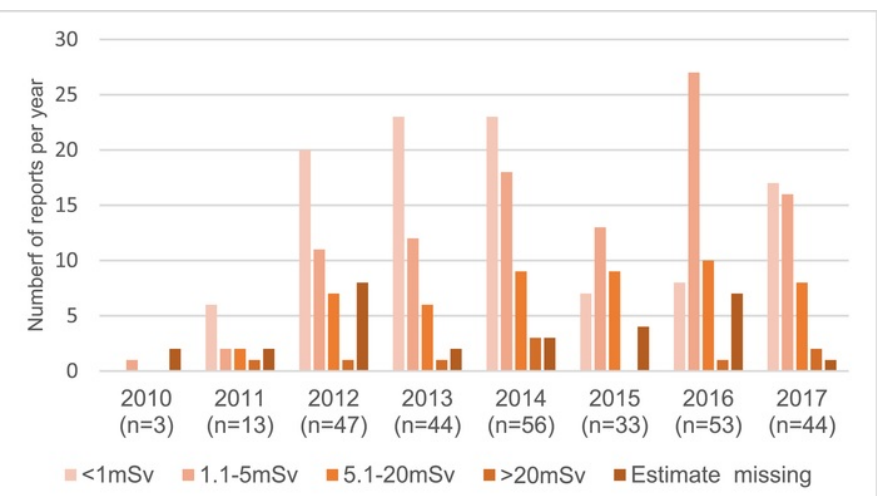

Figure 1 Number of reports and effective doses per year during 2010-2017 in Finland.

alt-text: Figure 1

\section{Unnecessary radiation doses}

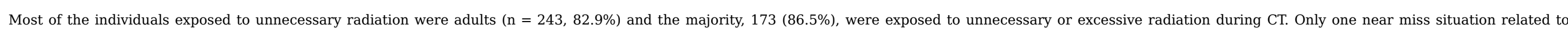

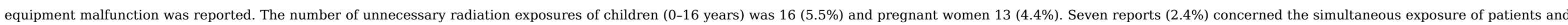


Table 1 Groups of individuals being exposed to unnecessary radiation by different radiological modalities during years 2010-2017 in Finland.

alt-text: Table 1

\begin{tabular}{|c|c|c|c|c|c|c|c|c|c|c|c|c|}
\hline \multirow[t]{2}{*}{ Modality } & \multicolumn{2}{|c|}{ Adult patient } & \multicolumn{2}{|c|}{ Childa } & \multicolumn{2}{|c|}{ Pregnant and foetus } & \multicolumn{2}{|c|}{ Hospital personnel } & \multicolumn{2}{|c|}{ Patient and staff } & \multicolumn{2}{|c|}{ Total } \\
\hline & $\mathrm{n}$ & $\%$ & $\mathrm{n}$ & $\%$ & $\mathrm{n}$ & $\%$ & $\mathrm{n}$ & $\%$ & $\mathrm{n}$ & $\%$ & $\mathrm{n}$ & $\%$ \\
\hline Radiography & 62 & 76.5 & 8 & 9.9 & 5 & 6.2 & 4 & 4.9 & 2 & 2.5 & 81 & 27.6 \\
\hline Computed Tomography & 173 & 86.5 & 8 & 4 & 6 & 3 & 9 & 4.5 & 4 & 2 & 200 & 68.3 \\
\hline Fluoroscopy & 5 & 62.5 & 0 & 0 & 2 & 25 & 0 & 0 & 1 & 12.5 & 8 & 2.7 \\
\hline Mammography & 2 & 100 & 0 & 0 & 0 & 0 & 0 & 0 & 0 & 0 & 2 & 0.7 \\
\hline Angiography & 1 & 50 & 0 & 0 & 0 & 0 & 1 & 50 & 0 & 0 & 2 & 0.7 \\
\hline Total & 243 & 82.9 & 16 & 5.5 & 13 & 4.4 & 14 & 4.8 & 7 & 2.4 & 293 & 100 \\
\hline
\end{tabular}

a 0 -16 years.

b more than one person exposed to radiation.

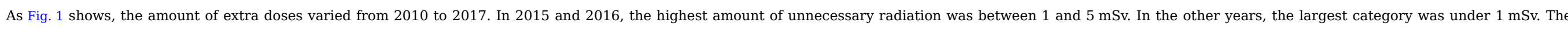

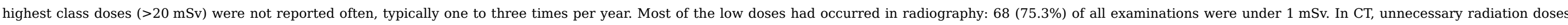

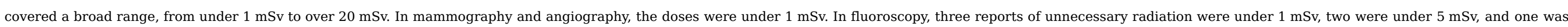
over $5 \mathrm{mSv}$ (Fig. 2).

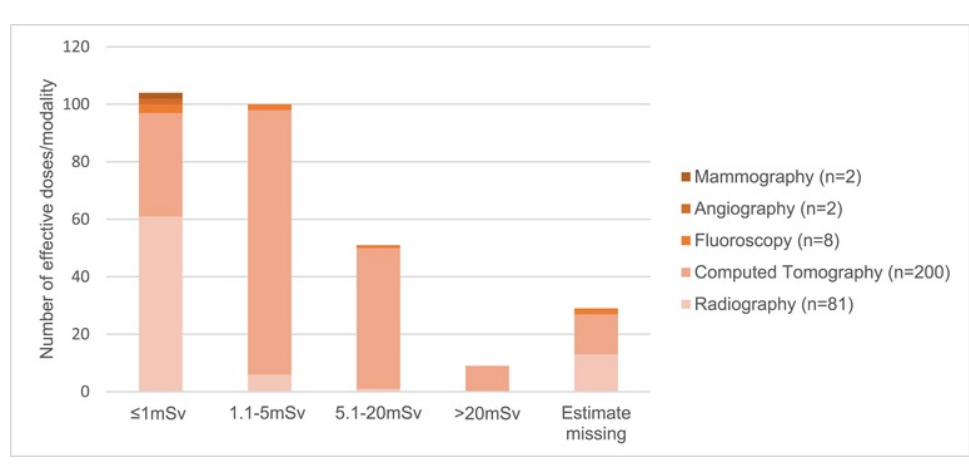

Figure 2 Estimated effective dose amounts of patient's unnecessary radiation in radiology modalities during years 2010-2017 in Finland. alt-text: Figure 2

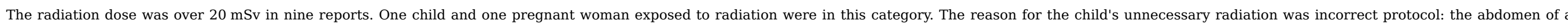

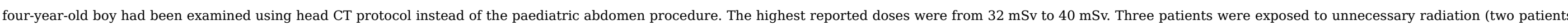

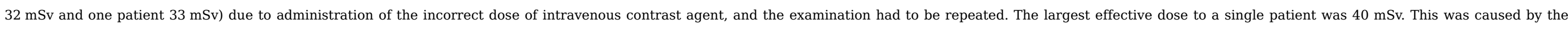
analysis technique being changed during a CT examination, resulting in unwanted ECG-gating throughout the examination.

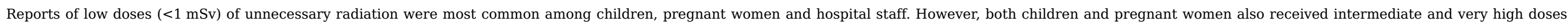
The largest estimated dose to a foetus was $34 \mathrm{mSv}$, during multiple examinations. In three other reports, the effective doses to a foetus during abdominal CT were estimated as $2.5 \mathrm{mSv}$, $8 \mathrm{mSv}$ and $9.8 \mathrm{mSv}$. 


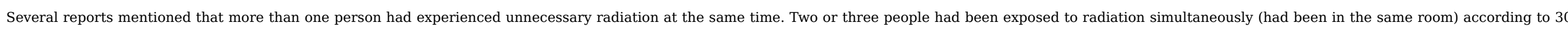

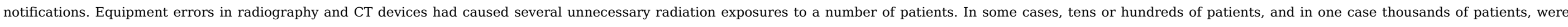

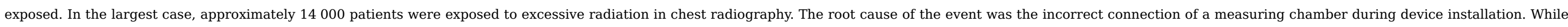
the faulty connection was active between 2008 and 2015, approximately 2000 patients per year had received an additional 0.015 mSv dose in postero-anterior chest radiograph.

\section{Reported causes of adverse events}

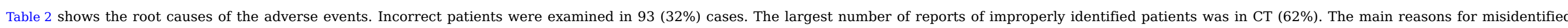

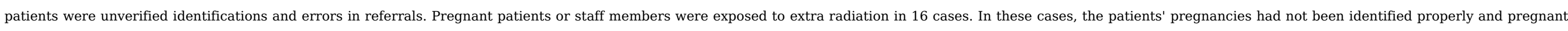
staff members were accidentally exposed to extra radiation.

Table 2 The reasons of adverse events expressed in reports to STUK ${ }^{\mathrm{a}}$ during years 2010-2017 in Finland. alt-text: Table 2

\begin{tabular}{|c|c|c|c|c|c|c|c|c|c|c|c|c|}
\hline \multirow[t]{2}{*}{ Modality } & \multicolumn{2}{|c|}{ Incorrect patient } & \multicolumn{2}{|c|}{ Pregnant patient or staff } & \multicolumn{2}{|c|}{ Equipment malfunction } & \multicolumn{2}{|c|}{$\begin{array}{l}\text { Human errors and } \\
\text { errors of } \\
\text { knowledge }\end{array}$} & \multicolumn{2}{|c|}{$\begin{array}{l}\text { Wrong procedure, } \\
\text { site or side }\end{array}$} & \multicolumn{2}{|c|}{ Total } \\
\hline & $\mathrm{n}$ & $\%$ & $\mathrm{n}$ & $\%$ & $\mathrm{n}$ & $\%$ & $\mathrm{n}$ & $\%$ & $\mathrm{n}$ & $\%$ & $\mathrm{n}$ & $\%$ \\
\hline Radiography & 34 & 37 & 5 & 31 & 16 & 44 & 14 & 24 & 12 & 13 & 81 & 28 \\
\hline Computed Tomography & 58 & 62 & 9 & 56 & 17 & 47 & 42 & 71 & 74 & 83 & 200 & 68 \\
\hline Fluoroscopy & 1 & 1 & 2 & 13 & 1 & 3 & 2 & 3 & 2 & 2 & 8 & 2 \\
\hline Mammography & 0 & 0 & 0 & 0 & 2 & 6 & 0 & 0 & 0 & 0 & 2 & 1 \\
\hline Angiography & 0 & 0 & 0 & 0 & 0 & 0 & 1 & 2 & 1 & 1 & 2 & 1 \\
\hline Total & 93 & 32 & 16 & 6 & 36 & 12 & 59 & 20 & 89 & 30 & 293 & 100 \\
\hline
\end{tabular}

a Radiation and Nuclear Safety Authority of Finland.

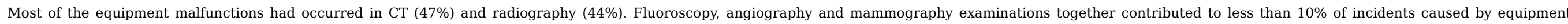
malfunctions. Examples of events following equipment faults were interrupted examinations, missing images, and service or installation faults. Poor image quality was mentioned twice.

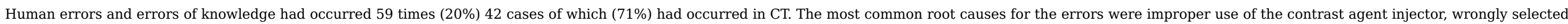
protocols, or incorrectly positioned slices. In radiography, the most often reported human error was imaging the wrong site or side. The majority of incorrect procedures (83\%) had occurred in CT.

\section{Discussion}

\section{Annual reports and radiation doses}

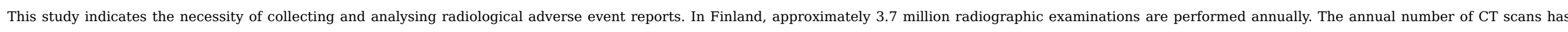

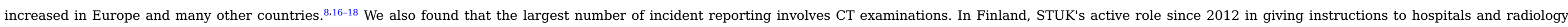
departments has boosted incident reporting and increased the number of annually received reports to almost 50 .

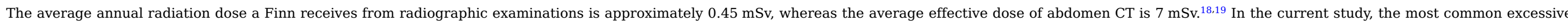

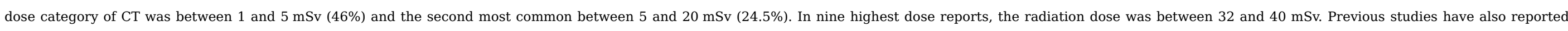

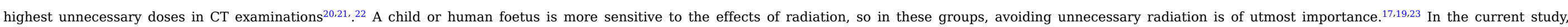




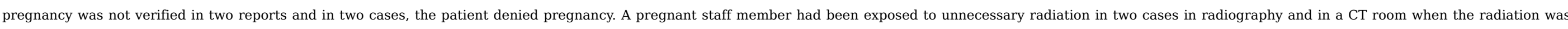

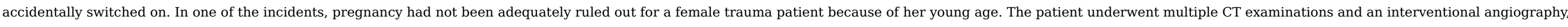

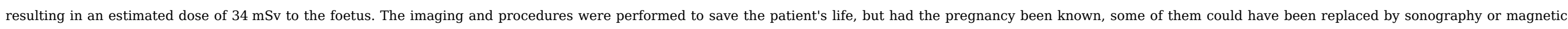
resonance imaging.

\section{Root cases of adverse events}

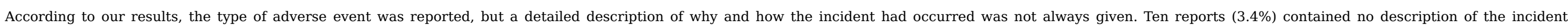

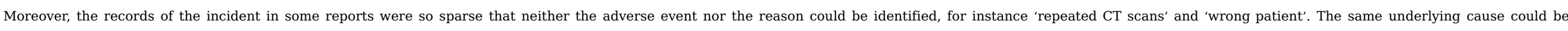

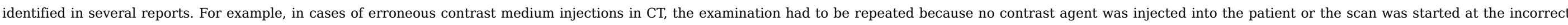
time point. Previous studies have reported similar findings. ${ }^{23,24}$

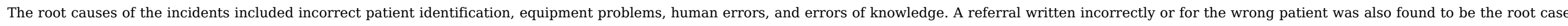

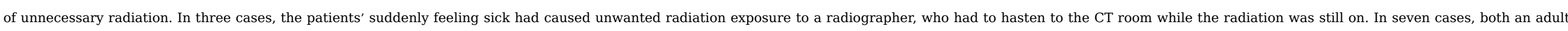

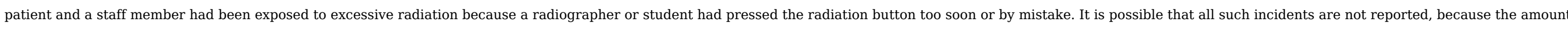

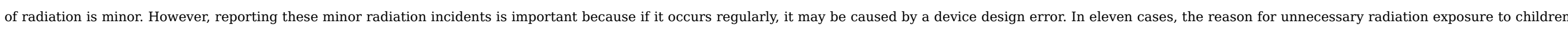
was a lack of knowledge regarding proper examination procedures, incorrect identification or improper administration of the contrast medium.

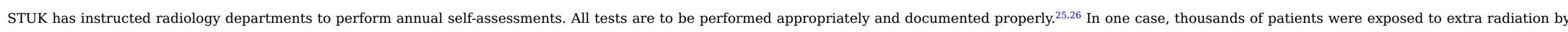

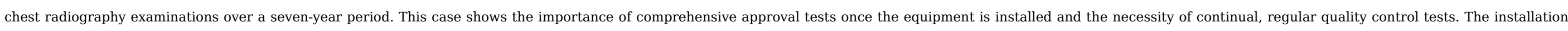
setup and tests of radiological equipment are crucial, because in the event of an error, the effects can be serious and far reaching.

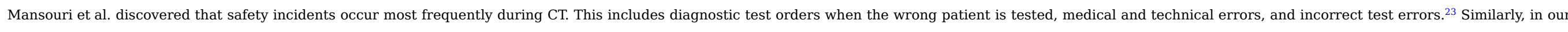

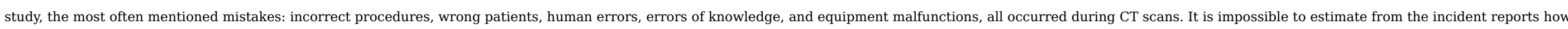
many of the mistakes were a result of knowledge or skill gaps. However, it is likely that the number of these faults could be decreased by means of education and training.

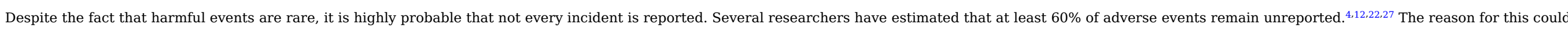

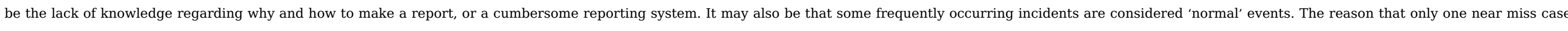

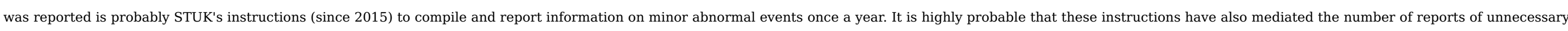

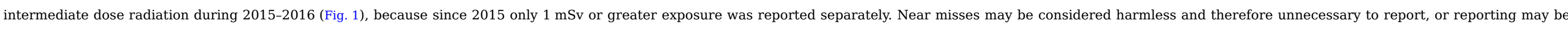

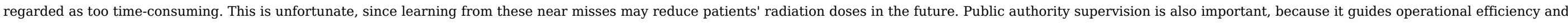
reporting methods.

\section{Limitations}

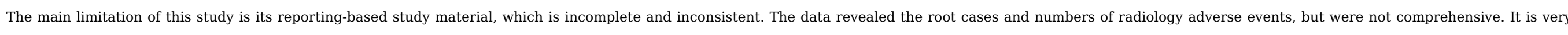

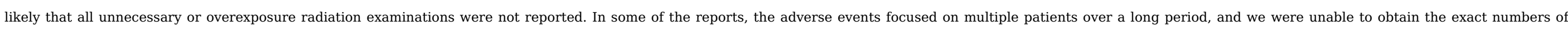

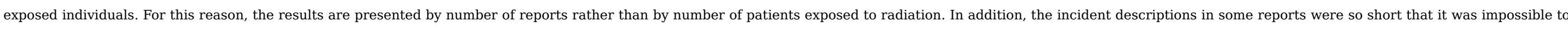
know what the preceding reasons for the incident were.

\section{Conclusion}

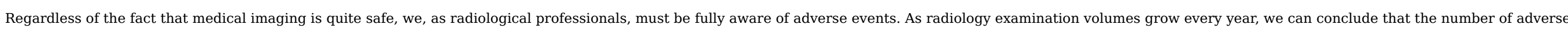

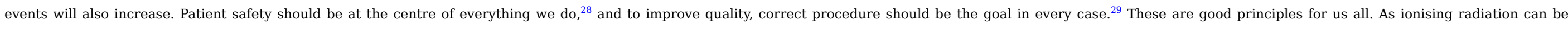




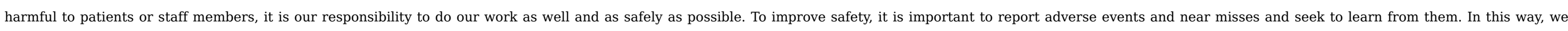
improve our safety culture for the benefit of the patient.

\section{Conflict of interest statement}

\section{None.}

\section{References}

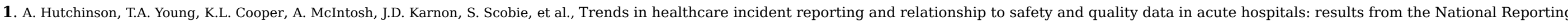
and Learning System, Qual Saf Health Care 18 (1), 2009 Feb, 5-10.

2. C. Wåhlin, S. Kvarnström, A. Öhrn and E. Nilsing Strid, Patient and healthcare worker safety risks and injuries. Learning from incident reporting, EurJ Physiother 2019 Jan 21 , 1-7.

3. C.A. Vincent, Analysis of clinical incidents: a window on the system not a search for root causes, Qual Saf Health Care 13 (4), 2004 Aug, $242-243$.

4. L.L. Leape, Reporting of adverse events, NEngl J Med 347, 2002, 1633-1638.

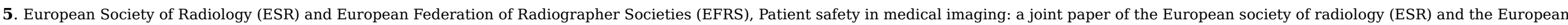
federation of radiographer societies (EFRS), Radiography 25 (2), 2019 May, e26-e38.

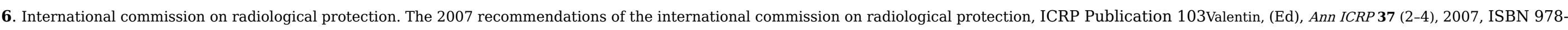
0-7020-3048-2.

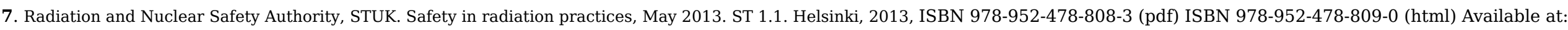
https://www.stuk.fi/en/web/en

8. J.B. Kruskal, B. Siewert, S.W. Anderson, R.L. Eisenberg and J. Sosna, Managing an acute adverse event in a radiology department, Radiographics 28 (5), 2008 , 1237-1250.

9. R.C. Newton, O.T. Mytton, R. Aggarwal, W.B. Runciman, M. Free, B. Fahlgren, et al., Making existing technology safer in healthcare, Qual Saf Health Care 19 (Suppl 2), 2010 , i15-i24.

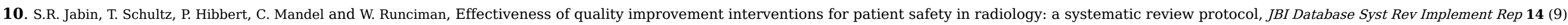
2016, 65-78.

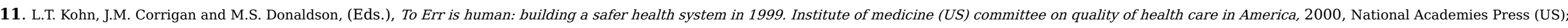
Washington (DC).

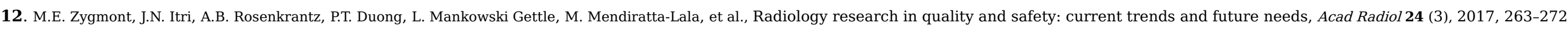

13. Radiation and Nuclear Safety Authority, STUK. Säteilylaki (Radiation law) 9.11.2018/859. Helsinki, 2018, Available at: https://www.stuklex.fi/en.

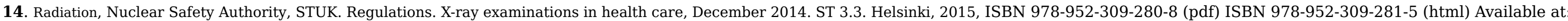
https://www.stuklex.fi/en/ohje/ST3-3\#a6

15. European Society of Radiology. ESR. Eurosafe imaging. Information for patients.http://www.eurosafeimaging.org/information-for-patients Last accessed August 2019.( 15. European Society of Radiology. ESR. Eurosafe Imaging. Information for patients. Last accessed February 2020. http://www.eurosafeimaging.org/information-for-patients )

16. V. Ruonala, (Ed), Number of radiological examinations in Finland in 2018. STUK-B 242, October 2019, Helsinki www.stuk.fi.

17. D.J. Brenner and E.J. Hall, Computed tomography - an increasing source of radiation exposure, N Engl J Med 357, 2007, $2277-2284$.

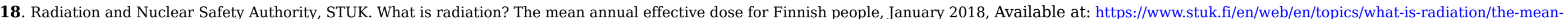


19. Radiation and Nuclear Safety Authority, STUK. Use of radiation in health care. Radiographic examinations. Radiation doses of radiographic examinations, September 2017, Available at: https://www.stuk.fi/en/web/en/topics/use-of-radiation-in-health-care/radiographic-examinations/radiation-doses-of-radiographic-examinations.

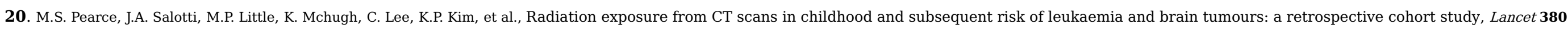
(9840), 2012, 499-505.

21. R.W. Harbron, What do recent epidemiological studies tell us about the risk of cancer from radiation doses typical of diagnostic radiography?, Radiography 22 (1), 2016, S41-S46.

22. M.S. Stecker, S. Balter, R.B. Towbin, et al., Guidelines for patient radiation dose management, J Vasc Intervent Radiol 20 (7), 2009 , S263-S273.

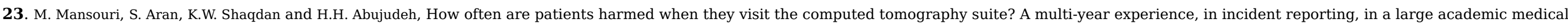
center, Eur Radiol 26 (7), 2016, 2064-2072.

24. R. Fazel, H.M. Krumholz, Y. Wang, J.S. Ross, J. Chen, H.H. Ting, et al., Exposure to low-dose ionizing radiation from medical imaging procedures, N Engl J Med 361 (9), 2009 , 849-857.

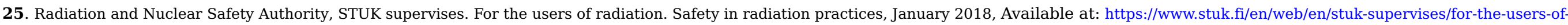
radiation/safety-in-radiation-practices.

26. G.P. Martin, L. McKee and M. Dixon-Woods, Beyond metrics? Utilizing 'soft intelligence' for healthcare quality and safety, Soc Sci Med 142, 2015 , $19-26$.

27. N.D. Jones, Where failures occur in the imaging care cycle: lessons from the radiology events register, J Am Coll Radiol 7 (8), $2010,593-602$.

28. J.P. McNulty and A.P. Brady, Patient safety: at the centre of all we do, Radiography 25 (2), 2019, 99-100.

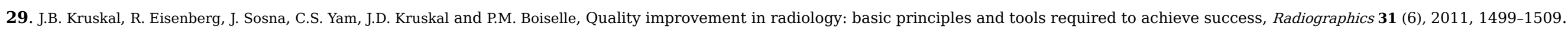

\section{Queries and Answers}

Query: The country name has been inserted for the affiliations "b" to "e". Please check, and correct if necessary.

Answer: It is ok

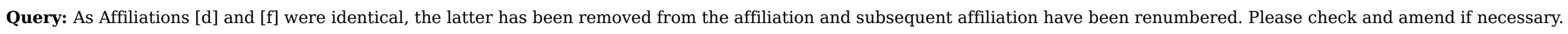
Answer: It is OK

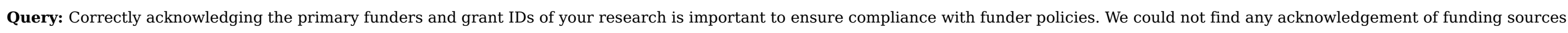
in your text. Is this correct?

Answer: Yes

Query: Please update Ref.15.

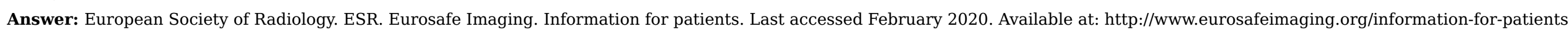

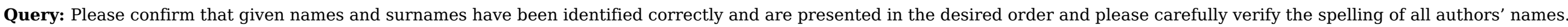

Answer: Yes , authors' names and surnames are identified correctly, but Jaakko Niinimäki's e-mail adress is jaakko.niinimaki@ppshp.fi

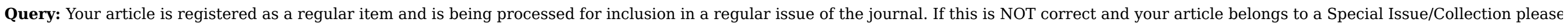
contact r.gibson@elsevier.com immediately prior to returning your corrections. 